\title{
O desafio da preservação do patrimônio histórico e cultural de Bagé: uma experiência de extensão
}

\section{Helyna Dewes}

helyna.dewes@gmail.com

\section{Alessandro Carvalho Bica}

alessandrobica@gmail.com

\section{Diogo Ferreira}

diogotrincafilmes@gmail.com

Universidade Federal do Pampa | Brasil

\section{Resumo}

A preservação do patrimônio histórico e cultural possibilita a aproximação com o passado, criando laços afetivos com as cidades e desenvolvendo um sentimento de pertencimento e de cuidado com os lugares compartilhados coletivamente. Por meio do projeto de extensão Desafio do Patrimônio a cidade de Bagé, no Rio Grande do Sul, pode ser relembrada e revivida, não apenas no seu aspecto arquitetônico, mas também na constituição da sua história e da sua memória. Além da visibilidade dada ao patrimônio material, o desenvolvimento do projeto possibilita a construção da memória coletiva por meio dos seus principais personagens que estão em bustos e em nomes de ruas, escolas e entidades.

\section{Palavras-chave}

Patrimônio, Educação, Cultura. 


\section{Introdução}

A cidade é uma construção realizada pelas pessoas que lá vivem suas rotinas, seu cotidiano. É onde nascem, crescem, trabalham, se divertem e, até mesmo, onde enterram seus mortos. 0 espaço urbano é um espaço coletivo no qual o presente, o passado e o futuro se mesclam nas vontades e nas ações de quem faz uso dele, resultando em um dinamismo que se reflete nas diferentes épocas vividas na cidade, as quais estão vivas e representadas, por exemplo, pela arquitetura.

No livro As cidades invisíveis, de Ítalo Calvino, as cidades são inventadas, construídas pela imaginação e pelo discurso de Marco Polo para contentar a vontade do grande imperador Kublai Khan em conhecer seus territórios. Conta o narrador da obra, comentando sobre a cidade de Zaíra:

Poderia falar de quantos degraus são feitas as ruas em forma de escada, da circunferência dos arcos dos pórticos, de quais lâminas de zinco são recobertos os tetos; mas sei que seria o mesmo que não dizer nada. A cidade não é feita disso, mas das relações entre as medidas do seu espaço e os acontecimentos do passado: a distância do solo até um lampião e os pés pendentes de um usurpador enforcado, o fio esticado do lampião à balaustrada em frente e os festões que empavesavam o percurso do cortejo nupcial da rainha; a altura daquela balaustrada e o salto do adúltero que foge de madrugada; a inclinação de um canal que escoa a água das chuvas e o passo majestoso de um gato que se introduz numa janela; a linha de tiro da canhoneira que surge inesperadamente atrás do cabo e a bomba que destrói o canal; os rasgos nas redes de pesca e os três velhos remendando as redes que, sentados no molhe, contam pela milésima vez a história da canhoneira do usurpador, que dizem ser o filho ilegítimo da rainha, abandonado de cueiro ali sobre o molhe.

A cidade se embebe como uma esponja dessa onda que reflui das recordações e se dilata. Uma descrição de Zaíra como é atualmente deveria conter todo o passado de Zaíra. Mas a cidade não conta o seu passado, ela o contém como as linhas da mão, escrito nos ângulos das ruas, nas grades das janelas, nos corrimãos das escadas, nas antenas dos para-raios, nos mastros das bandeiras, cada segmento riscado por arranhões, serradelas, entalhes, esfoladuras (CALVINO, 2003, p.15-16).

O passado da cidade, como descreve Marco Polo, é a própria cidade, pois ele está contido não apenas na sua materialidade, mas também nas histórias ali vividas e que ali são recontadas. Não é possível conhecer um lugar sem antes saber como se formou, em que época teve seu apogeu, quem por ali passou. Além disso, suas edificações, suas ruas e calçadas, suas praças e seus canteiros revelam como se configurava o espaço urbano nesses tempos idos. Seja pelo estilo de construções, seja pela utilização da força física e da capacidade intelectual dos homens, que empregaram suas motivações na constituição desses espaços. 
O desafio da preservação do patrimônio histórico e cultural de Bagé: uma experiência de extensão

Entretanto, para conhecer a história de uma cidade, é preciso primeiramente preservá-la. Do contrário, não há o que contar ou mostrar. Assim, a educação patrimonial torna-se um importante instrumento para a preservação e também para a divulgação da história e da cultura.

\section{0 desafio do patrimônio: extensão e educação patrimonial}

O projeto de extensão Desafio do Patrimônio foi desenvolvido inicialmente no ano de 2014, em Bagé. É uma ação integrante do Programa Institucional Guaman, pertencente à Universidade Federal do Pampa (UNIPAMPA), que visa desenvolver atividades de cunho cultural na instituição. O Desafio realizava-se por meio de um quiz, ou seja, um jogo de perguntas e respostas. Com publicações semanais em um jornal local de grande circulação, o jogo questionava ao público que lugar era aquele que estava retratado na fotografia veiculada. A fotografia poderia ser de um detalhe arquitetônico de um prédio histórico ou uma fotografia antiga de um lugar que sofreu alguma alteração. A resposta deveria ser enviada para o e-mail do projeto, o qual era sempre divulgado na coluna do jornal, resultando na entrega de um pequeno prêmio para o vencedor. As fotos foram publicadas oito meses. Toda a comunidade estava envolvida: o jornal com a coluna específica do projeto, o público do jornal que era formado pela população da cidade, e o comércio, que acabava conhecendo o projeto e fornecendo as premiações.

O Desafio também contou com atividades dentro da disciplina Fronteira e Sociedade do curso Licenciatura em Letras e Línguas Adicionais - Inglês, Espanhol e respectivas Literaturas, do Campus Bagé. Entre as ações de ensino desenvolvidas na disciplina, citam-se a visita ao Museu Dom Diogo de Souza e a realização de um seminário, onde os alunos pesquisaram e apresentaram os lugares históricos da cidade, material que foi utilizado para as publicações do jornal. Durante a visita ao Museu, os alunos puderam conhecer a história da cidade, sua relevância para a formação da fronteira ao sul do Brasil, os lugares e as personalidades relevantes para a Bagé. Essa aproximação proporcionou uma atividade de ensino diferente do convencional, principalmente em um curso de graduação, também pelo fato de muitos alunos serem oriundos de outras regiões do estado e do país.

O seminário realizado durante a disciplina resultou em um espaço de aprendizagem orientada, possibilitando a autonomia dos estudantes, uma vez que a história de Bagé está guardada principalmente nas bibliotecas municipais, dentro dos livros escritos pelos historiadores da cidade e nas narrativas contadas pelos moradores mais antigos, compartilhadas através dos tempos. 
O desafio da preservação do patrimônio histórico e cultural de Bagé: uma experiência de extensão

Complementando as ações iniciais do projeto, foi criada uma página em uma rede social, em que se compartilhavam fotos, matérias, desafios semanais e os vencedores de cada quiz. A divulgação por meio da internet mostrou-se uma ferramenta bastante eficaz para o alcance de um público mais jovem, o qual não era leitor assíduo do jornal, e tornou-se um repositório do projeto, pois até hoje a página do Desafio do Patrimônio recebe visitas e ganha novos seguidores.

\section{Bases históricas para construção do projeto}

Algumas considerações sobre o contexto histórico que envolve o projeto de extensão Desafio do Patrimônio merecem ser apresentadas, possibilitando uma compreensão ampla da relevância dessa cidade no contexto estadual e nacional. Na região da Campanha, onde se localiza o município de Bagé, a ocupação tem sua gênese através das estâncias estabelecidas pelos jesuítas espanhóis e imigrantes lusitanos no transcorrer do século XVII e XVIII. Estas regiões formam a chamada "fronteira seca" do Estado do Rio Grande do Sul, devido à existência de linhas demarcatórias imaginárias.

A Coroa Espanhola preocupada em impedir os avanços lusitanos na região das fronteiras gaúchas, edificou várias fortificações, como o Forte de Santa Tecla, em janeiro de 1774, na região próxima ao município de Bagé. 0 historiador João Antônio Cirne escreveu em 1897, no Almanak do Rio Grande do Sul, o seguinte relato ${ }^{1}$, sobre os apontamentos históricos do povoamento do município de Bagé:

[...] quando Portugal e Hespanha se ventilava a questão de limites das possessões americanas das duas nações, o general hespanhol D. João José Vertiz e Salcedo, vice-rei de Buenos Aires, marchou á frente de um exercito de cinco mil homens, com o propósito de conquistar todo o territorio desde a Colonia do Sacramento até o forte portuguez de Rio Pardo, e chegando ás cabeceiras do Rio Negro, escolheu uma posição vantajosa sobre a cochilia entre as principaes vertentes do dito rio e as do camaquam, Jaguarão e Ibicuhy, e neste ponto culminante traçou e fez construir uma fortaleza, a que o nome da virgem martyr Santa Thecla. Era o ponto mais avançado na frontera castelhana.

\footnotetext{
1 Em todas as citações transcritas de jornais e/ou outros documentos de época preservaram-se a linguagem usada para dar ao leitor uma visão mais acurada dos textos.

2 Sobre a importância do Tratado de Santo Ildelfonso na definição das fronteiras lusitanas em terras rio-grandenses, FERREIRA (1974, p. 57), traz o seguinte comentário: "Esse tratado, enormemente lesivo aos interesses brasileiros, não foi levado em consideração pelos rio-grandenses. [...] O período de Paz, sobrevindo ao Tratado de Santo Ildelfonso, foi benéfico ao desenvolvimento econômico da Capitania, estabilizando a população que, em parte, vivia meio nômade, segundo os azares da guerra e as oscilações das raias fronteiriças.
}

3 A expressão "Banda Oriental" era usada para definir a região da Cisplatina nas três primeiras décadas do século XIX, 
O desafio da preservação do patrimônio histórico e cultural de Bagé: uma experiência de extensão

Ademais, a construção do Forte de Santa Tecla está intimamente ligada à história das expansões castelhanas em território gaúcho, às guerras fronteiriças e às disputas bélicas pelo espaço geográfico do Estado do Rio Grande do Sul, bem como, ao início da ocupação do território que originará o município de Bagé, no limiar do século XIX. Outro fato importante, sobre a história do Forte de Santa de Tecla (Figura 1), é que a conquista do Forte pelas tropas portuguesas lideradas por Rafael Pinto Bandeira no ano de 1776, promoveu a manutenção do território português em solo rio-grandense no final do século XVIII.

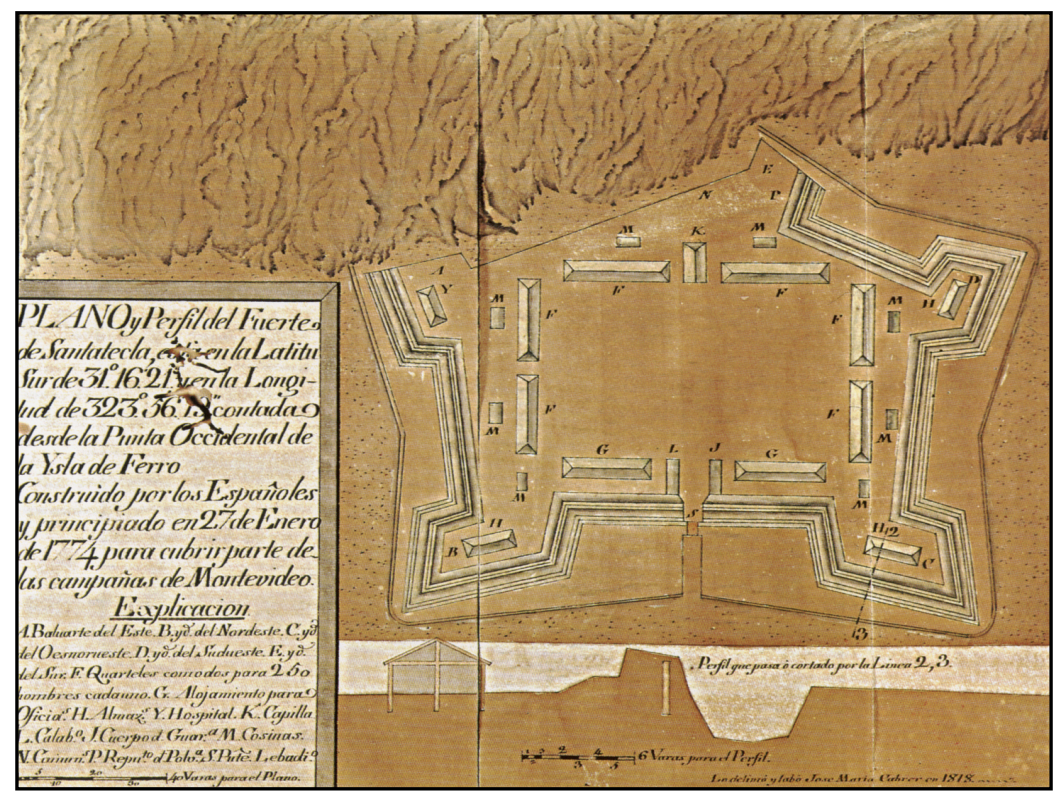

Figura 1: Imagem do Forte de Santa Tecla

Fonte: GOLIN, 2002, p. 392.

É possível compreender que estas regiões denominadas de fronteira seca foram se constituindo historicamente como espaços de lutas territoriais entre as coroas de Portugal e Espanha. Especificamente em relação à região da campanha, Reichel (2006, pág. 49, 50 -51), traz a seguinte consideração:

[...] o espaço da campanha, com sua população e riqueza pecuária,viu-se envolvido diretamente nessa disputa travada entre portugueses e espanhóis. Participou de escaramuças, sitiamentos, confiscos de mercadorías, contrabandos, formação de milicias, que se tornaram uma constante na região. [...] A disputa pelas terras da zona de fronteira intensificou-se, pois a riqueza ganadeira dessas era enorme. As duas coroas militarizaram a área, construindo fortes, destacando milícias de soldados e guardas de fronteiras. [...] Essa era a situação vivenciada pelos homens e mulheres que habitavam as terras localizadas na divida do Rio Grande do Sul com o Uruguai e com a Argentina. Eles experimentavam a fronteira nos seus dois sentidos: o de linha que separa $\mathrm{e}$ o de zona que aproxima.

A afirmação de Reichel corrobora na compreensão que na região de fronteira, seus habitantes fossem eles, portugueses, espanhóis, jesuítas ou índios vivenciaram durante todo o 
O desafio da preservação do patrimônio histórico e cultural de Bagé: uma experiência de extensão

século XVIII, o espelhamento das relações diplomáticas, bem como foram incluídos nos processos das disputas territoriais.

Estas escaramuças diplomáticas tentaram ser resolvidas novamente pela efetivação do Tratado de Santo Ildenfonso (1777):² o Estado português perdia os territórios localizados na região dos Sete Povos das Missões e da Colônia do Sacramento. Por outro lado, passava a ocupar a região dos Campos Neutrais, banhada pelas lagoas Mirim e Mangueira, onde se localizavam as atuais cidades de Santa Vitória do Palmar e Chui, promovendo uma maior e mais efetiva ocupação lusitana nas terras gaúchas.

A chegada do século XIX trouxe mudanças substanciais para o alargamento das fronteiras portuguesas no extremo-sul do País, isto é, mesmo com o estabelecimento dos novos limites em 1777, as belicosidades entre os homens que habitavam as terras rio-grandenses (Figura 2) não cessaram e os estigmas dos conflitos permaneciam, pois segundo Ferreira (1974, p. 60): "Se ao menos a nova fronteira trouxesse consigo o respeito e a paz entre os habitantes desta parte do continente, [...] Além, disso, a paz tão desejada [...] foi de curta duração". Neste cenário, percebe-se, que no início do século XIX, a assinatura do Tratado de Badajoz (1801), possibilitou que Portugal efetivasse e definisse suas fronteiras no Estado do Rio Grande do Sul, como se pode observar a seguir:

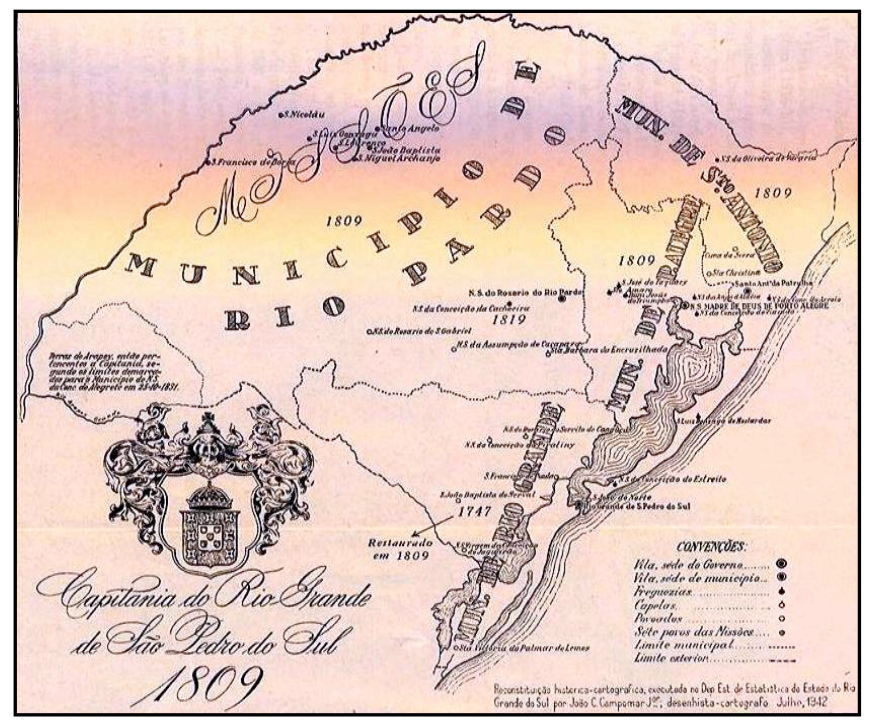

Figura 2: Capitania do Rio Grande de São Pedro do Sul.

Fonte: Acervo Iconográfico do Museu Dom Diogo de Souza

\footnotetext{
2 Sobre a importância do Tratado de Santo Ildelfonso na definição das fronteiras lusitanas em terras rio-grandenses, FERREIRA (1974, p. 57), traz o seguinte comentário: "Esse tratado, enormemente lesivo aos interesses brasileiros, não foi levado em consideração pelos rio-grandenses. [...] O período de Paz, sobrevindo ao Tratado de Santo Ildelfonso, foi benéfico ao desenvolvimento econômico da Capitania, estabilizando a população que, em parte, vivia meio nômade, segundo os azares da guerra e as oscilações das raias fronteiriças.
} 
O desafio da preservação do patrimônio histórico e cultural de Bagé: uma experiência de extensão

A transferência da Corte Portuguesa para o Brasil (1808) possibilitou uma ocupação e uma maior expansão sobre o território gaúcho, como também os movimentos de emancipação das colônias espanholas no sul, promovidos por José Artigas, contribuíram no desencadeamento de relações beligerantes na região da campanha.

Para reforçar a idéia da efetiva ocupação portuguesa na região da Campanha, o governo imperial promoveu a invasão da "Banda Oriental"3 em 1811 e 1816, com o objetivo especifico de expandir seus territórios sobre boa parte da região do Prata, na afirmação de Reichel (2006, p. 57): “O governo imperial português, [...] enviou tropas por terra e mar para atacar a Banda Oriental. As terrestres invadiram o território vizinho pela Capitania de São Pedro, [...] e acamparam junto à Fronteira Oeste". Neste contexto, os documentos oficiais e os historiadores bageenses apontam que a incursão militar realizada no ano de 1811, pelo português Dom Diogo de Souza, deu origem a fundação da cidade de Bagé. Ademais, a própria história da fundação do município confunde-se em muito aos interesses expansionistas, militares, políticos e econômicos, no transcorrer do período imperial e no período da República Velha. Sobre o momento inicial da formação do território de Bagé, o historiador Atilla Taborda (1959, p. 10) faz a seguinte afirmação:

Em princípios de 1811 acampou D. Diogo na região que corresponde hoje ao munícipio de Bajé. Dividiu o seu exército de observação em três colunas, sendo a primeira, que estacionou à margen direita do arrôio, nas proximidades dos cerros desta cidade, comandada pelo Gal. Manoel Marques de Souza. Nêste interim, apresentava-se o ensejo para a realização dos sonhos de conquista de D. Joao VI e D. Diogo. É que Buenos Aires independente envía uma declaração de guerra [...]. Em julo de 1811, o Gal. D. Diogo de Souza, move-se desta região com suas tropas e invade o Estado Oriental numa verdadeira marcha triunfal de vitórias sucessivas. [...] E foi daí, desse histórico acampamento de destemidos soldados luso-brasileiros, que surgiu está simpática cidade de Bajé, merecidamente chamada de "Rainha da Fronteira".

Ainda sobre ao início do povoamento do município de Bagé, Eurico Jacinto Salis (1955, p. 34 - 36) traz a seguinte consideração:

No ano de 1812, desenvolvia-se o novo núcleo de Bagé, nascido de um acampamento militar, [...] a população já possuía arraigados sentimentos religiosos [...]. Numa ação de profundo sentimento religioso [...] e em procissão transportam para a nova freguesia a preciosa imagem de S. Sebastião, talhada em madeira, com olhos amendoados, estilizando bela feição íncola e depositaram em um rancho, característico dos pampas sulinos, dos muitos que existiam no acampamento de Dom Diogo [...]. Construíram então, no local onde se acha a histórica matriz de S. Sebastião, a primeira capela de grande

${ }^{3}$ A expressão "Banda Oriental” era usada para definir a região da Cisplatina nas três primeiras décadas do século XIX, após as derrotas das campanhas separatistas de José Artigas na década de 1820 e a invasão portuguesa em 1816, recebe o nome de Colônia Cisplatina, pertencendo até o ano de 1828 ao território português. (REICHEL, 2006). 
O desafio da preservação do patrimônio histórico e cultural de Bagé: uma experiência de extensão

dimensão, feita em torrões de barro e coberta com capim santa-fé. [...] em 1814, a freguesia foi elevada à condição de curato, [...].

Percebe-se que a questão da religiosidade foi também uma tônica no processo de formação do município de Bagé: este fato pode ter relação direta e/ou indireta pelas características adversas vivenciadas pelos habitantes da campanha neste período e pela preocupação com o estigma que se tinha do Gaúcho, um homem sem lei e religião. Como afirma Gutfreind (2007),4 "habituados a uma vida independente e andarilha, os gaúchos representavam uma classe rebelde, responsável pelos crimes sociais para os proprietários de terra e do gado".

Logo a ocupação do território fronteiriço e a formação do município de Bagé, durante todo o século XIX, obedeceu a uma lógica da organização urbana das cidades que se localizavam nas regiões que viveram as transformações advindas das guerras territoriais ocorridas nos séculos anteriores.

Destaca-se, ainda, a Guerra da Cisplatina ${ }^{5}$ que pode ser definida como a conseqüência da disputa do território da Banda Oriental entre o Império Brasileiro e as Províncias Unidas do Rio da Prata. Iniciou-se em 1821, ano da anexação oficial da Banda Oriental ao território brasileiro com o nome de Província Cisplatina. Em 1825 temos a declaração de guerra das Províncias Unidas ao Império Brasileiro e encerrando-se em 1828, quando dos tratados de paz entre o Império e as Províncias Unidas com a formação da República Uruguaia.

Particularmente, este conflito teve consequências devastadoras para o município de Bagé, sendo seu território invadido pelas tropas do General e Ministro da Guerra argentino Carlos Maria de Alvear, como comenta Ferreira (1974, p. 86-87): "Alvear tomou a ofensiva, penetrando no território rio-grandense por Bagé, passando por São Gabriel, marchou na direção de Cacequi". Sobre este acontecimento, Taborda (1959, p. 12) traz o seguinte relato:

Por ocasião da guerra Cisplatina, Bajé viveu dias de verdadeiro pavor, quando da invasão do exército uruguaio-argentino, sob o comando do Gal. Carlos Maria de Alvear. As maiores infâmias foram cometidas, desde o sangue vergonhoso, o assassínio covarde, até a violação dos lares, a torpeza do desrespeito às famílias. Mas foi aqui, também, que esse indigno general sofreu a maior derrota. Foi aqui em Bajé que esse réles e ousado aventureiro encontrou uma jovem digna, que o enfrentou corajosamente, jogando-o à lama do chão, sem piedade para fugir depois pelo acampamento afora, [...] Foi esta sem duvida a maior derrota de

\footnotetext{
4 Não temos como objetivo deste trabalho, historicizar a questão do gaúcho e suas especificidades locais e/ou regionais, mas compreender o processo de formação do município de Bagé.

5 Especificamente sobre algumas especificidades da Guerra da Cisplatina, ver: MIRANDA, Marcia. A Estalagem e o Império: Crise do Antigo Regime, Fiscalidade e Fronteira na Província de São Pedro (1808-1831). Tese (Doutorado em Economia Aplicada) - Universidade Estadual de Campinas, Campinas, 2006; PEREIRA, Aline Pinto. Domínios e Império: 0 Tratado de 1825 e a Guerra da Cisplatina na Construção do Brasil. Dissertação de Mestrado em História, UFF, Niterói, 2007 e LAURENZANO, Cristina Mayra. Os Conflitos Platinos e a Formação do Estado. Dissertação de Mestrado em História Social, UEL, Londrina, 2008, entre outros escritos.
} 
O desafio da preservação do patrimônio histórico e cultural de Bagé: uma experiência de extensão

Alvear, porque as suas vitórias não as alcançava no campo da batalha, mas na satisfação dos seus instintos, na rapina, no saque, no opróbio, no desrespeito à dignidade humana.

Sendo assim, os acontecimentos transcorridos entre os anos de 1811 e 1846, que marcam a fundação do município de Bagé em 1811 e a elevação à condição de Vila, respectivamente, são ainda, grandes lacunas históricas no processo da construção das narrativas ${ }^{6}$ da vida da cidade.

Neste sentido, o processo de urbanização das regiões de fronteira e particularmente da cidade de Bagé, ocorreu principalmente devido aos desdobramentos políticos e acontecimentos econômicos durante todo o século XIX. Visto que nestas regiões, a sociedade refletia no seu imaginário uma sociedade guerreira e militarizada do século XVIII e as aspirações econômicas da nascente elite sul-rio-grandense que irá se estabelecer no século XIX.

Sobre o processo de urbanização ocorrido na fronteira do Rio Grande do Sul, durante o século XIX e a formação das cidades nestas regiões, Ramos (2006) traz o seguinte relato:

O alargamento do território para o sul e para oeste e a fundação de povoados, capelas e vilas estão vinculados à expansão desejada pelos luso-brasileiros e à incorporação de tais espaços como resultado dos tratados coloniais que se estabeleceram ainda no período colonial. A importância das cidades na fronteira oeste está exatamente na necessidade de povoar esses espaços, garantindo efetivamente a posse de tais lugares ao Império brasileiro.

Neste mesmo texto, Ramos (2006, p. 442 - 443), ao relatar o processo de desenvolvimento e ocupação das cidades localizadas na fronteira oeste, bem como, sobre os aspectos econômicos, culturais e sociais ocorridos nestes movimentos urbanos, traz os seguintes comentários sobre a cidade de Bagé no século XIX:

A nascente povoação foi elevada a vila em 1846 e a cidade 13 anos depois, em razão de sua considerável expansão. Quanto ao aspecto urbano, Bagé apresentava-se bem urbanizada com suas 33 ruas, cinco praças e mais de mil casas, [...]. Apesar da ocupação militar em seu nascedouro, a atividade econômica de Bagé estava concentrada na pecuária e na charqueada. 0 processo de urbanização era, então, ampliado na medida em que esses grandes proprietários deslocavam-se para o espaço urbano, erguendo ali suas casas, em especial na rua Sete de Setembro. Tais prédios, assobradados ou não, eram um atestado da riqueza. As famílias dos fazendeiros, entretanto, continuavam morando no interior e a casa da cidade era usada por ocasião das festas

60 conceito usado neste sentido tem como objetivo evidenciar a importância das narrativas históricas na construção da escrita da História, isto é, entendemos a expressão "narrativa histórica" como um processo que permite articular o historiador e seus objetos de pesquisa, neste sentido, é preciso levar em conta também que o ato de relativizar a verdade, foi uma conquista significativa para a historiografia. As narrativas históricas contemporâneas não podem perder de vista certa busca pelo verdadeiro. A historiografia pode e deve ser concebida como um movimento constante de releituras do passado, compreendidas como reinterpretações do passado que são passiveis de perdas, equívocos e revisões. Sobre este assunto, sugere-se a leitura de CERTEAU (1982), HOBSBAWN (1998) e LE GOFF (2003). 
O desafio da preservação do patrimônio histórico e cultural de Bagé: uma experiência de extensão

religiosas do Divino Espírito Santo ou de São Sebastião, padroeiro da cidade. A essa sociabilidade de caráter religioso juntava-se a desenvolvida pelos comerciantes, que, dada sua importância e poder econômico, construíram o Clube Comercial e o teatro para peças teatrais, bailes e festas sociais e em cujos espaços as elites locais costumavam se reunir (grifo nosso).

Compreende-se que, apesar da incursão militar que promoveu a ocupação do território do município de Bagé a partir dos anos de 1811, o desenvolvimento urbano, cultural e social esteve intimamente ligado aos aspectos econômicos da pecuária e da produção charqueadora. Como também pelo surgimento do comércio, obedecendo a uma lógica estrutural e às dinâmicas econômicas recorrentes no processo de formação do território rio-grandense durante o século XIX, principalmente nas regiões fronteiriças.

De fato, a formação histórico-econômica do Estado do Rio Grande do Sul tem suas origens na doação de sesmarias e na formação de estâncias no século XVIII e no estabelecimento da indústria saladeiril durante o século XIX. As consequências deste processo de ocupação das terras rio-grandenses relegaram por muitas vezes ao Estado gaúcho, uma posição de fornecedor de produtos primários agrícolas e de pecuária, tais como, o charque e o couro para outras províncias, como também para o mercado externo durante todo período Imperial e durante algumas décadas da República da história brasileira.

Os processos políticos e sociais desencadeados durante todo o século XIX no Brasil provocaram mudanças substanciais nas relações econômicas e nas dinâmicas sociais no findar do século XIX no Rio Grande do Sul. Estas mudanças podem ser associadas ao processo de enfraquecimento da indústria saladeiril, à transição do trabalho escravo para o trabalho assalariado, à manutenção da produção pecuária e agrícola, ao incentivo à imigração européia, ao desenvolvimento urbano e aos discursos de modernidade pelos republicanos.

Logo, ao final do século XIX, o Estado do Rio Grande do Sul sofria com a crise da economia baseada na grande propriedade rural, na pecuária e nas charqueadas, agravada em muito pela imobilidade de seus representantes políticos em relação aos políticos de outras regiões brasileiras, prejudicando assim, os interesses econômicos gaúchos.

Sandra Pesavento, em sua obra A Burguesia Gaúcha: Dominação do Capital e Disciplina do Trabalho (1988) discute a formação e a afirmação do empresariado industrial no Rio Grande do Sul no período da Primeira República e como estes grupos assumiram características capitalistas e burguesas no desenrolar do século XIX e nas primeiras décadas do século XX. Neste sentido, 
O desafio da preservação do patrimônio histórico e cultural de Bagé: uma experiência de extensão

interessante é a descrição realizada sobre a Charqueada Santa Thereza ${ }^{7}$ de Bagé, onde Pesavento (1988, 59-82) analisa algumas das ações empresarias que ultrapassavam o espaço da empresa saladeiril e compunham uma ótica de submissão do trabalho ao capital:

Na Charqueda Santa Thereza, do Visconde de Ribeiro de Magalhães estabelecida em Bagé, funcionava na primeira década do século, um colégio misto para 60 alunos, sendo o professor pago pela Intendência Municipal. [...] Em uma biografia feita sobre o Visconde, há referências de que o empresário havia, estabelecido hospital de caridade, farmácia, restaurante popular, escola e armazém, e teatro onde se realizavam exibições cinematográficas. [...] No ramo do beneficiamento da carne, a propriedade de Visconde Ribeiro de Magalhães (Charqueda Santa Thereza) apresentava, já em 1909, casas de material construídas para abrigar o pessoal do estabelecimento, que se elevava a 894 pessoas (operários e suas famílias), bem como uma capela para atender as

necessidades de culto.

Observa-se que, mesmo com a crise estabelecida nas charqueadas, no período da Primeira República, a Charqueada Santa Thereza conseguiu manter a "dominação do capital sobre o trabalho" associando práticas assistencialistas com um fim de dominação do trabalho humano. A indústria pecuária localizada na Campanha gaúcha teve no período da Republica Velha um status econômico extremamente relevante nas relações do mercado interno, como também no enriquecimento da cidade de Bagé. A incorporação da produção saladeiril no final do século XIX produziu uma mudança estrutural fundamental na construção de uma sociedade economicamente abastada na região da campanha. Haja vista, que o ciclo charqueador da Zona Sul do Estado entrava paulatinamente em franca decadência pelas mudanças ocorridas com o fim da escravidão e pela concorrência com o charque platino.

\section{A importância da preservação do patrimônio cultural e histórico}

0 tombamento do centro histórico de Bagé, realizado pelo Instituto de Patrimônio Histórico e Artístico do Estado do Rio Grande do Sul (IPHAE) no ano de 2012 evidenciou a necessidade de preservação de um conjunto arquitetônico que possui relevância dentro do contexto estadual e nacional. Contudo, essa medida causou uma série de respostas negativas da

7 Em tempo, cabe salientar que a Charqueada Santa Thereza de Bagé foi estabelecida no ano de 1897 no município de Bagé, tendo como seu proprietário o Visconde Ribeiro de Magalhães e que na visão de muitos historiadores incorporou idéias liberais na produção do Charque, bem como, na manutenção da ordem social sobre seus empregados e no progresso econômico de sua produção fabril. Sobre a Charqueada Santa Thereza, consultar as obras de: BOUCINHAS, Cláudio A. A História das Charqueadas de Bagé (1891 - 1940) na Literatura. Dissertação de Mestrado em História, PUCRS, 1993; FAGUNDES, Elizabeth Macedo. Vila de Santa Thereza. [S. I: S. N], 1999. SOARES, Fernanda Codevilla. Santa Thereza: Um Estudo sobre as Charqueadas da Fronteira Brasil-Uruguai. Dissertação de Mestrado em Integração Latino Americana, UFSM, 2006. 
O desafio da preservação do patrimônio histórico e cultural de Bagé: uma experiência de extensão

comunidade, principalmente por parte dos proprietários de imóveis situados na área central. Ao realizar o processo de tombamento sem a devida sensibilização e conscientização da população, a administração municipal e o IPHAE geraram um clima de antipatia à questão da preservação do patrimônio histórico e cultural da cidade.

Mas, por que é importante preservar o patrimônio cultural e histórico de uma cidade? 0 patrimônio cultural é tudo aquilo que possui valor para as sociedades e que, de alguma forma, é preservado, constrói sentidos e sentimentos para as pessoas. Ele conta a história de um povo, ao mesmo tempo em que faz parte da vida cotidiana.

No Dicionário Crítico de Política Cultural, Teixeira Coelho (1997) explica que o patrimônio cultural é responsável por manter, construir ou reconstruir as identidades pessoais ou coletivas, proporcionando a sensação de segurança, vinculando indivíduos e grupos às suas tradições. Configura-se assim, como um marco dentro dacultura, necessitando atenção e pressupondo a necessidade de manutenção por parte daqueles que compartilham os mesmos costumes, hábitos, crenças e valores. Conforme a Constituição Federal, artigo 216 (CUNHA FILHO, 2002, p. 98),

\footnotetext{
Constitui o patrimônio cultural brasileiro os bens de natureza material e imaterial, tomados individualmente ou em conjunto, portadores de referência à identidade, à ação, à memória dos diferentes grupos formadores da sociedade brasileira, nos quais se incluem:

I - as formas de expressão

II - os modos de criar, fazer e viver;

III - as criações artísticas, científicas e tecnológicas;

IV - as obras, objetos, documentos, edificações e demais espaços destinados às manifestações artístico-culturais;

$\mathrm{V}$ - os conjuntos urbanos e sítios de valor histórico, paisagístico, artístico, arqueológico, paleontológico, ecológico e científico.
}

O patrimônio cultural materializa-se, então, nas criações artísticas e intelectuais, individuais e coletivas que possuem importância para todos os indivíduos que formam aquela cultura. Contribuindo com essa conceituação, Grunberg (2007) acrescenta que as sociedades recebem o patrimônio cultural, usufruem, alteram, somam elementos conforme suas necessidades, preocupando-se com a preservação ou esquecendo esses bens. E muito próximo ao conceito de patrimônio cultural está o de patrimônio histórico. Todos aqueles bens que contam a história de um lugar, que fazem parte da origem de um povo e que continuam a ser preservados a fim de dar continuidade à identidade de um grupo, constituem esse patrimônio.

Torna-se importante questionar, então, para quem é importante o patrimônio? Segundo Pedro Funari e Sandra Pelegrini (2009) é preciso considerar os valores sociais ao longo do tempo, pois são eles que determinam como o patrimônio foi e é visto por cada comunidade. Desse modo, cada sociedade constrói o seu patrimônio, isto é, preserva, mantém ou altera todos 
O desafio da preservação do patrimônio histórico e cultural de Bagé: uma experiência de extensão

os bens e obras que considera relevante para a construção da sua identificação enquanto grupo social. Portanto, é importante considerar, em um estudo que trata sobre patrimônio, o quanto as comunidades consideram esses bens, o uso que fazem e, a partir disso, as transformações realizadas para adaptar ao uso. Além da necessidade de identificar e analisar os bens que constituem o patrimônio cultural há a preocupação em manter viva na memória das pessoas toda a significação contida nesses bens. Afinal, o sentido de patrimônio cultural só tem continuidade se ele está também conservado dentro das pessoas.

Para tanto, a educação patrimonial faz-se imprescindível, pois é somente através dela que o patrimônio poderá ser conhecido, valorizado, preservado e, assim, continuar vivo para as comunidades. Nesta mesma direção, Horta, Grunberg e Monteiro (1999, p. 6), afirmam que a

Educação Patrimonial é um instrumento de "alfabetização cultural" que possibilita ao indivíduo fazer a leitura do mundo que o rodeia, levando-o à compreensão do universo sociocultural e da trajetória histórico-temporal em que está inserido. Este processo leva ao reforço da autoestima dos indivíduos e comunidades e à valorização da cultura brasileira, compreendida como múltipla e plural.

Partindo-se dessas considerações, nota-se o quanto são necessárias ações de educação patrimonial com o intuito de construir um sentimento de pertencimento e para desenvolver a noção de preservação dos bens culturais e históricos de cada sociedade. Somente assim, poderão ser evitadas as demolições, o abandono e a depredação tão constantes ao patrimônio das cidades. A educação patrimonial proporciona aos indivíduos o conhecimento sobre a sua cultura, evitando assim uma "deseducação coletiva" (LEMOS, 2000, p. 84), impedindo que se permitam atitudes estritamente políticas, comerciais ou de interesses somente particulares em relação ao patrimônio.

\section{Novas perspectivas para o Desafio do Patrimônio}

Após um ano de pausa para reestruturação, o projeto retornou em 2016 com uma proposta renovada. Mantendo o viés da educação patrimonial, nesta edição o foco do projeto são as personalidades históricas da cidade. Para a seleção dessas personalidades, buscou-se investigar a vida de cidadãos proeminentes nascidos em Bagé, que dão nomes a ruas, que possuem bustos ou estátuas nas praças, políticos, intelectuais, artistas, enfim, todos aqueles que contribuíram com a cidade e que levaram o nome de Bagé para outros lugares. 
O desafio da preservação do patrimônio histórico e cultural de Bagé: uma experiência de extensão

As atividades, desenvolvidas principalmente via internet, constituíram-se no aproveitamento da página do projeto, já bastante conhecida pelo público do Desafio do Patrimônio, e na criação e compartilhamento de vídeos curtos, contando a história de vida de uma determinada personalidade e sua importância para a cidade. 0 conteúdo dos vídeos surge através dos textos produzidos pelos alunos da disciplina Fronteira e Sociedade do curso de Letras do campus Bagé. 0 objetivo, seguir, foi possibilitar que mais pessoas tivessem acesso à história da cidade, dessa vez, contada a partir dos seus principais personagens.

\section{Considerações finais}

A educação patrimonial possibilita que os cidadãos conheçam e se apropriem sua história e cultura. Esse sentimento de pertencimento, de coletividade, de preocupação com os bens da cidade, faz com que seus habitantes busquem sempre o melhor para o local onde vivem, diminuindo, assim, os casos de vandalismo ou contribuindo para uma noção de preservação.

O projeto de extensão Desafio do Patrimônio vem buscando sensibilizar a população de Bagé para a preservação de seus bens: seus prédios históricos, suas praças, suas ruas. Juntamente, um dos princípios do projeto é através da construção e do compartilhamento do conhecimento, possibilitar que a população se aproprie desses conteúdos.

Algumas repostas positivas já foram obtidas: durante a realização dos seminários em sala de aula, nos comentários da rede social, em apresentações do projeto em eventos acadêmicos. Contudo, faz-se necessário que o poder público, seja no âmbito municipal ou federal, também cumpra o seu papel na preservação dos bens históricos e culturais do município, tendo em vista que é ele quem normatiza e define critérios para obras, restaurações, e novas construções. Infelizmente, ações desses poderes não estão sincronizadas, contribuindo ainda mais para o descaso com relação à preservação desses bens. Espera-se que ainda mais pessoas possam ter acesso à história da cidade, dos seus bens e dos seus personagens, gerando um sentimento cada vez maior de pertença e de responsabilidade que cada cidadão deve ter com a sua cidade.

\section{Referências}

CALVINO, Ítalo. As cidades invisíveis. Rio de janeiro: O Globo; São Paulo: Folha de S. Paulo, 2003.

CERTEAU, Michel. A Escrita da História. Rio de Janeiro: Forense Universitária, 2007. 
COELHO, Teixeira. Dicionário crítico de política cultural. São Paulo: Iluminuras, 1997.

CUNHA FILHO, Francisco Humberto. Teoria e prática da gestão cultural. Fortaleza: Universidade de Fortaleza, 2002.

DREHER, Martin N. As religiões. In: História Geral do Rio Grande do Sul. 1 ed. Passo Fundo: Méritos, 2007. v. 2, Império.

FERREIRA, Arthur Filho. História Geral do Rio Grande do Sul: 1503-1974. 4 ed. Porto Alegre: Editora Globo, 1974.

FUNARI, Pedro Paulo Abreu; PELEGRINI, Sandra de Cássia Araújo. Patrimônio histórico e Cultural. Rio de Janeiro: Jorge Zahar, 2009.

GOLIN, Tau. A Fronteira: governos e movimentos espontâneos na fixação dos limites do Brasil com o Uruguai e a Argentina. Porto Alegre: L\&PM, 2002.

GUTFREIND, Ieda. O Gaúcho e a sua cultura. In: História Geral do Rio Grande do Sul. 1aㅡ Ed. Passo Fundo: Méritos, 2007, v.1, Colônia.

GRUNBerg, Evelina. Manual de Atividades Práticas de Educação Patrimonial. Brasília: IPHAN, 2007. Disponível em: <http://www.iphan.gov.br/portal/baixaFcdAnexo.do?id=3837> Acesso em: 24 mar. 2016.

HOBSBAWN, Eric. A volta da narrativa. In: Sobre História. São Paulo: Companhia das Letras, 1998.

HORTA, Maria de Lourdes Parreiras; GRUNBERG, Evelina; MONTEIRO, Adriane Queiroz. Guia Básico de Educação Patrimonial. Brasília: Instituto do Patrimônio Histórico e Artístico Nacional / Museu Imperial, 1999.

LE GOFF, Jacques. História. In: História e memória. São Paulo: Editora da Unicamp, 2003.

LEMIESZEK, Claúdio de Leão. Bagé: Relatos de sua História. Porto Alegre: Martins Livreiro, 1997.

LEMOS, Carlos A. C. 0 que é Patrimônio Histórico. São Paulo: Brasiliense, 2000.

PESAVENTO, Sandra Jatahy. A burguesia gaúcha: dominação do capital e disciplina do trabalho no Rio Grande do Sul (1889-1930). Porto Alegre: Mercado Aberto, 1988.

PICCOLO, Helga. Vida política no século XIX. Porto Alegre: Ed. UFRGS, 1992.

RAMOS, E. H. C. L.. Cidades e sociabilidades (1822 - 1889). In: História Geral do Rio Grande do Sul - Império l. 1 ed. Passo Fundo: Méritos Editora, 2006, v. 2.

REICHEL, Heloísa Jochims. Fronteiras do Espaço Platino. In: História Geral do Rio Grande do Sul. 1aㅡ. Ed. Passo Fundo: Méritos, 2006, v.1.

SALIS, Eurico Jacinto. História de Bagé: ama tua terra quem bem conhece. Porto Alegre: Livraria do Globo S.A., 1955. 
O desafio da preservação do patrimônio histórico e cultural de Bagé: uma experiência de extensão

SOARES, Fernanda Codevilla. Santa Thereza: Um Estudo sobre as Charqueadas da Fronteira Brasil-Uruguai. Dissertação de Mestrado. Universidade Federal de Santa Maria, Programa de Pós-Graduação em Integração Latino Americana, Santa Maria, 2006.

SOUZA, Susana Blein de. Identidade e nacionalismo no processo de integração da fronteira uruguaia no final do século XIX. In: Humanas. Globalização, Nacionalismo e Regionalização. Porto Alegre, IFCH/UFRGS, v. 18, n.12, jan.-dez. 1995.

TABORDA, Attila. Bajé na História. Bajé: Tipografia Cetuba, 1959.

The challenge of preserving the historical and cultural heritage of Bage: an extension of experience

\begin{abstract}
The preservation of historical and cultural heritage makes possible to approach with the past, creating emotional ties with the cities and developing a sense of belonging and care for the places shared collectively. Through the extension project "Heritage Challenge" the city of Bage, Rio Grande do Sul, can be remembered and revived, not only in its architectural aspect, but also in the constitution of its history and its memory. In addition to the material given asset visibility, project development allows the construction of collective memory through its main characters that are busts and names of streets, schools and entities.
\end{abstract}

\section{Keywords}

Heritage, Education, Culture.

Original submetido em: 5 maio 2016

Aceito para publicação em: 13 jan. 2017
El reto de la preservación del patrimonio histórico y cultural de Bagé: una experiencia de extensión

\begin{abstract}
Resumen
La conservación del patrimonio histórico y cultural hace que sea posible acercarse con el pasado, creando lazos emocionales con las ciudades y el desarrollo de un sentido de pertenencia y el cuidado de los lugares compartidos colectivamente. A través del proyecto de extensión Desafio do Patrimônio la ciudad de Bagé, Río Grande do Sul, pudo ser recordada y revivida, no sólo en su aspecto arquitectónico, sino también en la constitución de su historia y su memoria. Además del la visibilidad que se fue dada al patrimonio material, el desarrollo del proyecto permite la construcción de la memoria colectiva a través de sus personajes principales que son bustos $y$ nombres de calles, escuelas y entidades.
\end{abstract}

Palabras clave

Patrimonio, Educación y Cultura.

Sobre os autores:

Helyna Dewes, Alessandro Carvalho Bica e Diogo Ferreira atuam na Universidade Federal do Pampa (RS, Brasil). 